\title{
Ethel García Buchard (coordinadora), Imaginarios de la nación y de la ciudadanía en Centroamérica
}

\section{Víctor Hugo Acuña Ortega ${ }^{1}$}

Me ha interesado este libro porque quería enterarme de los desarrollos recientes de los estudios históricos sobre la nación en Centroamérica, iniciados con los trabajos de Steven Palmer hace ya tres décadas. En este comentario voy a tratar de plantear algunas ideas sobre la compilación en su conjunto, centrado en la cuestión de la invención nacional, y no me voy a referir a cada uno de los trabajos en específico, ya que son temáticamente muy diversos.

La obra, que se abre con una presentación de la coordinadora, está dividida en tres partes y siete capítulos. La primera parte titulada "Construyendo un nuevo orden: prácticas, imaginarios y cultura política" incluye el artículo de Eduardo Madrigal "Cultura política, espacios públicos, poderes e imaginarios en la Costa Rica de las Cortes de Cádiz", que muestra la continuidad de las élites costarricenses, un grupo con estrechos lazos de parentesco, entre fines del periodo colonial, el proceso gaditano y la independencia. $Y$ el de Ethel García "Juramentación constitucional y ritualización del poder en la sociedad hondureña. Primeras décadas del siglo XIX”, que intenta seguir el difícil tránsito, en el plano de la legitimación del poder carnal y concreto del monarca al poder abstracto de la constitución.

La segunda parte titulada "La teatralidad del poder y la legitimación por los nuevos sujetos políticos" está integrada por el ensayo de Minor Carrera "La diosa Minerva como testigo de la Guatemala ideal en el imaginario liberal (1898-1920)", que estudia las famosas y estrafalarias fiestas en honor a esa diosa del mundo antiguo organizadas durante la dictadura de Manuel Estrada Cabrera, y el de Patricia Fumero "Aproximaciones a la cultura política: Centroamérica y la conmemoración del centenario (septiembre 1921)", que analiza los festejos del centenario de la independencia de Centroamérica realizados en Guatemala.

En fin, la tercera parte incluye el trabajo de Laura Raabe "Una academia de bellas artes en Costa Rica: modernidad, nación y género (1897-1914)", que reconstruye los primeros pasos de esa institución educativa, con un alumnado femenino mayoritario, y las funciones que el Estado costarricense pretendió atribuirle en relación con la cultura nacional; el de Eugenia Zava-

1 Costarricense. Doctor en Historia por l'Ecole des Hautes Etudes en Sciences Sociales-Université de Paris, Sorbonne (Paris IV). Profesor emérito de la Escuela de Historia de la Universidad de Costa Rica. Correo electrónico: vhacuna@gmail.com 
leta "Impulso estatal al quehacer artístico de Costa Rica (1950-1980)", que se ocupa de las políticas estatales en relación con las artes plásticas en los años dorados del reformismo, y el de Patricia Alvarenga "En busca de los invisibles hilos del discurso. Narrativas de intelectuales centroamericanos: Carlos Monge Alfaro, Pablo Antonio Cuadra y Roque Dalton", que analiza los diseños de nación, a partir de una mirada a la historia, propuestos por esos tres intelectuales centroamericanos, respectivamente costarricense, nicaragüense y salvadoreño.

En efecto, como se observa en la mayoría de los trabajos de este libro, el ritual y el ceremonial son prácticas indispensables para la legitimación política tanto en las sociedades sin Estado como en los imperios y los estados nacionales. En este sentido, su estudio es una vía adecuada para la comprensión del funcionamiento del poder. Aunque ya lo sabemos, es útil recordar que la formación política predominante en las sociedades con Estado han sido los imperios los cuales han existido desde ya hace varios milenios. También conviene reiterar que las naciones han aparecido solamente en los últimos dos siglos y medio, e incluso los estados nacionales más poderosos han sido estados imperiales, Gran Bretaña, Francia, Estados Unidos, entre otros. Se debe enfatizar que las naciones, si bien como dice Benedict Anderson son artefactos culturales, son un tipo específico de artefacto cultural, es decir, un artefacto político cuyo fin es ejercer el poder y legitimar o cristalizar relaciones de dominación.

Procedo ahora a plantear las reflexiones en forma de interrogantes, que me han suscitado los trabajos reunidos en este libro. En primer lugar, surge la pregunta sobre ¿quién es el representado o simbolizado, el objeto del ritual o de la política? El representado es plural, ya que puede ser el Estado o el régimen político (Ethel García); el gobernante como el déspota guatemalteco Manuel Estrada Cabrera (Minor Carrera) y, en fin, la nación propiamente dicha como aparece en todos los otros trabajos, salvo el de Eduardo Madrigal.

En segundo lugar, ¿quiénes son la comunidad política, su sujeto o sus sujetos? Aquí también aparece el fenómeno de la pluralidad y se plantea la cuestión de la ciudadanía: los "notables" (Eduardo Madrigal) o la "oligarquía" (Patricia Alvarenga), ciudadanos abstractos, el pueblo, "mesías", "ciego", o "charral" (Patricia Alvarenga), grupos sociales concretos, étnicos como los indígenas o económicos como los labriegos sencillos costarricenses, los artesanos o la "clase obrera", entre otros. Surge aquí el problema de las exclusiones de las naciones, ya que nunca integran a todos los habitantes ni en la comunidad imaginada, ni en la comunidad de ciudadanos, como fue por mucho tiempo el caso de las mujeres. No hay nación que incluya de manera universal, si la pertenencia pasa por atribuciones de signos; posiblemente, la única nación que no excluiría sería aquella que renuncie a la fabricación de una identidad y se limite a la construcción de ciudadanía, es decir, que fije lo nacional en los deberes y derechos establecidos por la constitución, como dice Habermas. 
En tercer lugar, surge la oportuna interrogante ¿cuál nación?, pregunta que en Centroamérica nunca ha tenido una respuesta inequívoca, ya que podría ser la "patria grande", la "patria chica", una región con vocación irredenta o un ensamble de grupos étnicos. De esta pluralidad de opciones da testimonio el trabajo de Patricia Fumero, en donde la nación celebrada en el centenario de la independencia es una Centroamérica que nunca llegó a formarse y no la Guatemala realmente existente. Dicha fluctuación de afiliaciones es el fundamento de separatismos y anexionismos que marcan la historia de las naciones.

En cuarto lugar, se plantea el problema de cómo las naciones se hacen reconocibles frente a propios y a extraños. ¿Cuáles son las señas de identidad de la nación, sus diacríticos, según las distintas etapas de su invención? Este aspecto es uno de los más complejos y exige una reconsideración continua en el estudio de los fenómenos nacionales. La nación es una convocatoria continua, el plebiscito diario del que hablaba Renan, que unas veces aglutina y otras suscita indiferencia. En estos trabajos encontramos una variedad de instrumentos y recursos de elaboración de señas de identidad por parte de las naciones ístmicas: políticas culturales al servicio de la difusión de signos de pertenencia que operan como mecanismos de integración, homogeneización y exclusión (Eugenia Zavaleta); diacríticos eficaces y diacríticos que no interpelan; señales que son de gran prioridad o señales de baja prioridad (Laura Raabe); señales producidas para el pueblo y señales elaboradas para la élite como el arte nacional coleccionable (Eugenia Zavaleta); íconos y logos que se hacen circular profusamente como la carreta pintada; atributos morales o cívicos o raciales propagandizados en el discurso político; un grupo humano o una región que funcionan como metonimias o núcleo representativo de la nación; una serie de instituciones que pueden ser del Estado y no automáticamente de la nación (Laura Raabe); diseños de la nación por ideólogos e intelectuales que no son lo mismo que políticas de realización de la idea nacional (Patricia Alvarenga). Esto plantea la cuestión de lo supuestamente auténtico en una comunidad nacional, aunque es conocido que la fabricación de signos de pertenencia nacional es siempre artificio o invención de tradiciones, poco importa que sean materiales importados o productos locales los utilizados.

En quinto lugar, algunos de estos trabajan suscitan la interrogante: ¿desde cuándo hay nación? El tema de la antigüedad de las naciones en general y la de cada una de ellas en particular es siempre una cuestión que genera debates entre los especialistas y disputas con los nacionalistas que incansablemente defienden la supuesta cuasi-eternidad de su nación. La edad de la nación es un tema en discusión entre quienes han estudiado la invención de la nación en Costa Rica, ¿nación desde la época de Juan Rafael Mora o nación solamente a partir de la época liberal? (Laura Raabe). La pregunta sobre su edad remite al asunto de las temporalidades de las naciones, es decir, a sus relaciones 
con el pasado y con el futuro. La nación se representa siempre como memoria y en ese sentido opera sobre la base de una selectividad del pasado, por ejemplo, con tal y no con este otro pasado, con mucho pasado o con poco pasado (Patricia Fumero). De este modo, las naciones se inscriben en determinados regímenes de historicidad en donde el énfasis puede ser la proyección o más bien la conservación (Patricia Alvarenga). De todos modos, las naciones son el artefacto por excelencia del régimen de historicidad de futuro pasado; la nación es siempre proyecto, aunque este sea reaccionario.

Como se puede observar, los trabajos de este libro suscitan algunas de las principales interrogantes que se plantean en los estudios actuales de las naciones y, en este sentido, su publicación es bienvenida y su lectura puede resultar provechosa e inspiradora como así ha sido en mi caso.

\section{Referencia}

García Buchard, Ethel (Coord.). (2017). Imaginarios de la nación y de la ciudadanía en Centroamérica. San José: EUCR. 